\title{
Influence of Emitter Structure on Its Hydraulic Performance Based on the Vortex
}

\author{
Cuncai Wang, Zhiqin Li * and Juanjuan Ma
}

Citation: Wang, C.; Li, Z.; Ma, J. Influence of Emitter Structure on Its Hydraulic Performance Based on the Vortex. Agriculture 2021, 11, 508. https://doi.org/10.3390/ agriculture 11060508

Academic Editors: Ivan Francisco Garcia Tejero and Victor Hugo Durán-Zuazo

Received: 19 April 2021

Accepted: 27 May 2021

Published: 30 May 2021

Publisher's Note: MDPI stays neutral with regard to jurisdictional claims in published maps and institutional affiliations.

Copyright: (c) 2021 by the authors. Licensee MDPI, Basel, Switzerland. This article is an open access article distributed under the terms and conditions of the Creative Commons Attribution (CC BY) license (https:// creativecommons.org/licenses/by/ $4.0 /)$.
School of Water Resources Science and Engineering, Taiyuan University of Technology, Taiyuan 030024, China; wangcuncai0485@link.tyut.edu.cn (C.W.); majuanjuan@tyut.edu.cn (J.M.)

* Correspondence: lizhiqin@tyut.edu.cn; Tel.: +86-136-0358-3918

\begin{abstract}
The rectangular labyrinth emitter is taken as the study object in this article, as we added internal teeth to vortex-free and vortex areas in its lateral channel or lengthened the vertical channel, to change the channel structure. Using the computational fluid dynamics (CFD) method simulates the water flow field, to get the relationship between flow rate and pressure, and the vortexes distribution in channel. The aim of this study is to explore the reasons for the influence of structural change on hydraulic performance of the emitter through the analysis of vortex intensity and its distribution from the perspective of the vortex. The results show that the relative error of simulated results and experimental data was $1.02-2.11 \%$. Adding internal teeth to vortex-free areas in lateral channel can improve hydraulic performance of the emitter; adding them to vortex areas can reduce it. The increase in vortex number and intensity in flow field is the internal reason for the improvement of the emitter's hydraulic performance. The channel structure changes promote the formation of a larger velocity gradient, and the increase in the velocity gradient in flow field exacerbates vortex formation. Changing channel structure to improve the emitter's hydraulic performance can promote an increase in the number and intensity of vortexes in the channel.
\end{abstract}

Keywords: labyrinth emitter; channel structure; vortex; hydraulic performance; CFD simulation

\section{Introduction}

Emitters are key components of drip irrigation systems; their hydraulic performance directly determines the working performance of drip irrigation systems [1-3]. An emitter with superior hydraulic performance has low flow rate sensitivity to inlet pressure and can better ensure the irrigation uniformity of drip irrigation systems. The hydraulic performance of the emitter is usually expressed as:

$$
q=k \cdot h^{x}
$$

where $k$ is the flow coefficient; $\mathrm{x}$ is the flow index; $q$ is the flow rate of the emitter, $\mathrm{L} / \mathrm{h}$; and $h$ is the inlet pressure head of the emitter, $\mathrm{m}[4]$.

The hydraulic performance of the emitter depends on its channel structure, size, and material [5]. In recent years, studies have shown that emitters of the labyrinth channel have superior hydraulic performance when compared with other types of emitters. For this reason, in recent years, many authors have conducted considerable amounts of research on the relationship between channel structural parameters and the flow index and flow coefficient, especially the flow index, striving to reduce it by changing the channel structure of the emitter in order to improve its hydraulic performance. Yu et al. [6] studied the relationship among five key structural parameters and the flow index and flow coefficient through the orthogonal experimental design method, and gave the regression equations regressed by the linear multivariable regression method regarding the relationship between the flow coefficient and flow index and the structural parameters. Xie et al. [7] analyzed the influence of the tooth angle and pitch on the flow coefficient and flow index, indicating 
that the tooth angle, tooth pitch, and flow coefficient are positively correlated, and the flow coefficient increased with the increase in the tooth angle and pitch. Tang et al. [8] noted that the flow index of the drip irrigation emitter decreased with the increase in the emitter draft angle, the angle of the tooth tip, and the distance between the opposite tooth tips, which also decreased with the decrease in the fillet radius of the tooth tip, additionally, the flow index is unrelated to the changes in the height of the channel. Tian et al. [9] selected nine major structural parameters, using multivariable regression methods, to establish the regression equations regarding the relationship between the flow index and flow coefficient with the nine structural parameters, in the process of their research.

The sensitivity of flow rate to the inlet pressure not only depends on the flow index but is also affected by the flow coefficient. Therefore, the study of the hydraulic performance of the emitter should analyze the slope of its flow rate-pressure curve. In addition, most of the literature is devoted to studying the relationship between channel structure parameters and the flow index and the significance analysis of the influence of channel structure parameters on the flow index $[10,11]$. Many scholars have also conducted related research regarding the energy dissipation mechanism in the channel of the labyrinth emitter. Yan et al. [12] revealed the correlation relationship between the dentate structure of the flow path of emitters and energy dissipation. The results showed that the rears of dentations and dentate tips were the primary regions for energy dissipation. Xing et al. [13] analyzed the energy dissipation mechanism of perforated drip irrigation emitters. The results showed that the main energy consumption of PDIE was due to the mixing of two streams formed by the scalariform perforation plate. However, they only revealed the energy dissipation in the flow channel. The research on the internal reason for the flow channel structure causing the change in the hydraulic performance of the emitter, that is, the mechanism study of the influence of channel structure on the emitter's hydraulic performance, is inadequate.

In this article, we use a larger channel cross section $(1.5 \mathrm{~mm} \times 1.5 \mathrm{~mm})$ to ensure the anti-clogging performance of the emitter, and, at the same time, we add internal teeth ( $0.5 \mathrm{~mm}$ high) to the channel to enhance the hydraulic performance. The section size after the internal teeth is bigger than the clogging sensitive size $(0.7 \mathrm{~mm})$ [14-17]. We change the channel structure of the emitter by adding internal teeth to the channel of the commonly used rectangular labyrinth emitter. The aims of this study are as follows: to analyze the internal reasons for the change in the hydraulic performance of the emitter caused by the structural parameter change from the perspective of the vortex; to explore the correlation among the structure of the emitter, the vortex, and the hydraulic performance; and, to provide a certain theoretical and reference basis for the research and development of irrigation emitters.

\section{Materials and Methods}

\subsection{Emitter Structure and Parameters}

In this paper, adding different numbers of internal teeth to vortex-free and vortex areas in the lateral channel of different units of the rectangular labyrinth emitter (A emitter) forms the internal-tooth labyrinth emitters (B, C emitters). At the same time, in order to further study the relevance of the emitter's structure, vortex, and hydraulic performance, the vertical channel of each unit of the A emitter was lengthened to 5 times (D emitter) for comparison. This made the head loss increase caused by the lengthening of the channel equal the head loss increase caused by adding 15 teeth to vortex-free areas in the lateral channel of different units ( $B_{1}$ emitter), at $10 \mathrm{~m}$ inlet pressure head. Each model of emitter consisted of 45 units, and the cross section of the flow channel was $1.5 \mathrm{~mm} \times 1.5 \mathrm{~mm}$ (width $\times$ depth). The dimensions of the internal teeth were as follows: $0.5 \mathrm{~mm}$ high and $1 \mathrm{~mm}$ wide; the thickness of the internal teeth was consistent with the depth of the channel. The teeth were placed from the beginning of channel units. The parameters of the emitters are shown in Table 1 and Figure 1, and the physical model of A emitter is shown in Figure 2. 
Table 1. The structure and parameters of the emitters.

\begin{tabular}{cccc}
\hline Type & Internal Teeth Position & Schematic & Tooth Numbers \\
\hline $\mathrm{A}$ & $/$ & 0 \\
\hline $\mathrm{B}_{1}$ & vortex-free area & 15 \\
\hline $\mathrm{B}_{2}$ & vortex-free area & 30 \\
\hline $\mathrm{B}_{3}$ & vortex-free area & 45 \\
\hline $\mathrm{C}_{1}$ & vortex area & 30 \\
\hline $\mathrm{C}_{2}$ & vortex area & 45 \\
\hline $\mathrm{C}_{3}$ & vortex area & \\
\hline $\mathrm{D}$ & $/$ & 0 \\
\hline
\end{tabular}

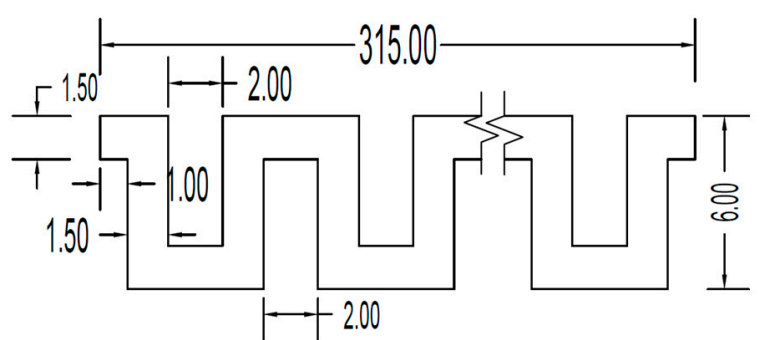

(a)

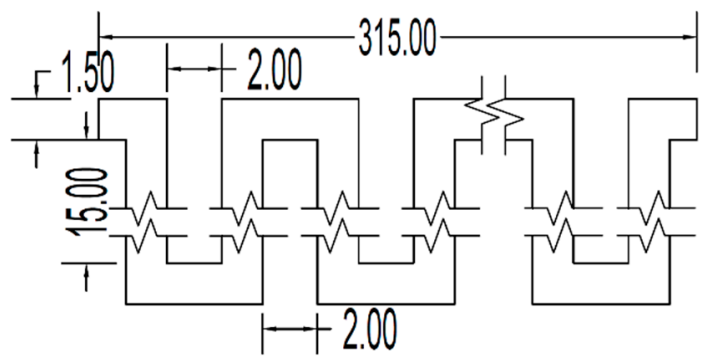

(b)

Figure 1. Dimensions of emitters (mm). (a) Dimensions of A emitter; (b) Dimensions of D emitter.

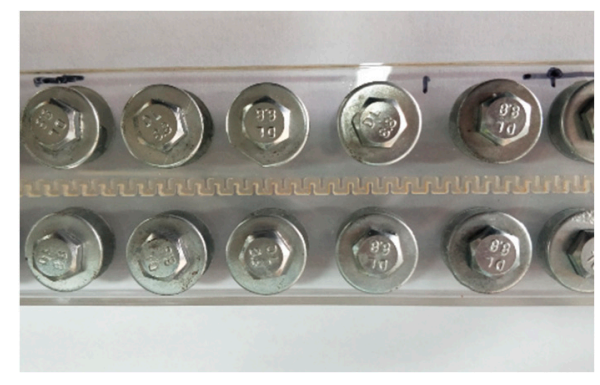

Figure 2. Physical model of A emitter. 


\subsection{Control Equations and Calculation Model}

The water movement in the emitter can be regarded as the movement of incompressible fluid. The basic control equations are composed of the continuity equation and the Navier-Stokes equation [18]. Using FLUENT software for simulation calculation, studies have shown that the standard $k-\varepsilon$ model of the labyrinth emitter calculation is consistent with the actual situation [19-21]. Thus, the calculation model selects standard $k-\varepsilon$ model. The velocity and pressure coupling are solved by the SIMPLE algorithm, and the convergence accuracy is 0.0001 .

Continuity equation:

$$
\frac{\partial u}{\partial x}+\frac{\partial v}{\partial y}+\frac{\partial w}{\partial z}=0
$$

Navier-Stokes equation:

$$
\begin{gathered}
\frac{(\partial(\rho u))}{\partial t}+\nabla \cdot(\rho u U)=-\frac{\partial p}{\partial x}+\mu \nabla^{2} u+\rho f_{x} \\
\frac{(\partial(\rho v))}{\partial t}+\nabla \cdot(\rho v U)=-\frac{\partial p}{\partial y}+\mu \nabla^{2} v+\rho f_{y} \\
\frac{(\partial(\rho w))}{\partial t}+\nabla \cdot(\rho w U)=-\frac{\partial p}{\partial z}+\mu \nabla^{2} w+\rho f_{z}
\end{gathered}
$$

where $U$ is the velocity; $u, v, w$ are the velocity components in the $x, y, z$ coordinate axes; $\rho$ is the density of water, $\mathrm{kg} / \mathrm{m}^{3} ; \mu$ is viscosity, $\mathrm{Pa} \cdot \mathrm{s} ; \boldsymbol{p}$ is pressure, $\mathrm{Pa}$; and $f_{x}, f_{y}, f_{z}$ are the components of mass force, regardless of mass force.

$k$ equation:

$$
\frac{\partial(\rho k)}{\partial t}+\frac{\partial\left(\rho k u_{i}\right)}{\left(\partial x_{i}\right)}=\frac{\partial}{\left(\partial x_{j}\right)}\left[\left(\mu+\frac{\mu_{t}}{\sigma_{k}}\right) \frac{\partial k}{\left(\partial x_{j}\right)}\right]+G_{k}-\rho \varepsilon
$$

$\varepsilon$ equation:

$$
\frac{\partial(\rho \varepsilon)}{\partial t}+\frac{\partial\left(\rho \varepsilon u_{i}\right)}{\left(\partial x_{i}\right)}=\frac{\partial}{\left(\partial x_{j}\right)}\left[\left(\mu+\frac{\mu_{t}}{\sigma_{\varepsilon}}\right) \frac{\partial \varepsilon}{\left(\partial x_{j}\right)}\right]+\frac{\left(C_{1 \varepsilon} \varepsilon\right)}{k} G_{k}-C_{2 \varepsilon} \frac{\varepsilon^{2}}{k}
$$

Among them,

$$
\begin{gathered}
G_{k}=\mu_{t}\left(\frac{\partial u_{i}}{\partial x_{j}}+\frac{\partial u_{j}}{\partial x_{i}}\right) \frac{\partial u_{i}}{\partial x_{j}} \\
\mu_{t}=\rho C_{\mu} \frac{k^{2}}{\varepsilon}
\end{gathered}
$$

where $k$ is turbulent energy; $\varepsilon$ is the turbulent dissipation rate; $\mu_{t}$ is turbulent viscosity; $t$ is time; $\mu$ is viscosity; $x_{i}, x_{j}$ is the coordinate tensor; and $G_{k}$ is the production term of turbulent energy $k$ caused by the average velocity gradient; The empirical constants are $C_{1 \varepsilon}=1.44, C_{2 \varepsilon}=1.92, C_{\mu}=0.09, \sigma_{k}=1.0$, and $\sigma_{\varepsilon}=1.3$ [22].

\subsection{Boundary Conditions and Mesh}

The boundary layer in the channel of the emitter was set to encrypt the grid. The first boundary layer was $0.01 \mathrm{~mm}$, and the other layers were increased by a ratio of 1.5; there were 6 boundary layers in total with $0.21 \mathrm{~mm}$. In order to ensure high computational efficiency and to reduce the influence of the mesh on the calculation results, the grid sizes of $0.15,0.12,0.1,0.09,0.08,0.07,0.06,0.05$, and $0.04 \mathrm{~mm}$, were selected to calculate the flow rate of the emitter under the inlet pressure head of $5 \mathrm{~m}, 10 \mathrm{~m}$, and $15 \mathrm{~m}$. Considering the calculation accuracy and efficiency, when the average difference of the calculation results was less than $0.5 \%$, it was assumed that the number of grids does not influence the results. 
When the grid size was $0.08 \mathrm{~mm}$, the average difference was $0.38 \%$; therefore, the grid size was set as $0.08 \mathrm{~mm}$, as shown in Figure 3.

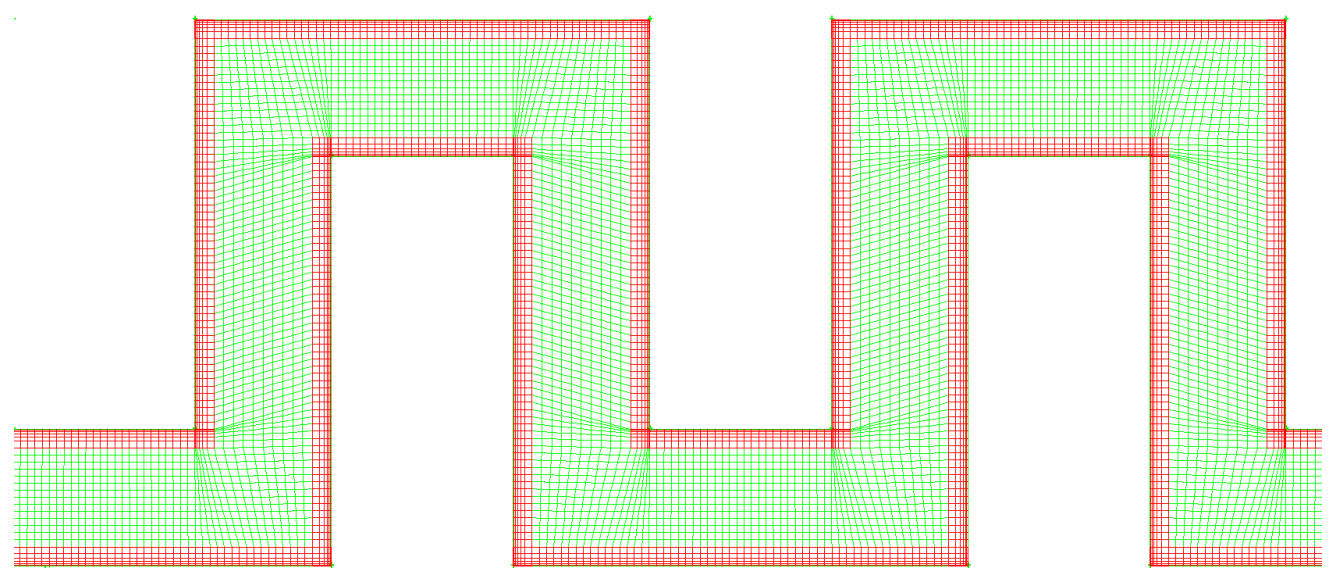

Figure 3. Grid division of the emitter.

The initial condition was $0.6-1.1 \mathrm{~m} / \mathrm{s}$ inlet velocity, and the outlet condition was outflow. The standard wall function method was used to process the wall surface of the channel, and the wall surface roughness was $0.01 \mathrm{~mm}$ [23].

\section{Results and Discussion}

\subsection{Analysis of the Accuracy of the Simulated Results}

The verification of this numerical simulation calculation results was conducted using the experimental data in the reference document [24]. The relative error of the simulated results and the experimental data of the triangular labyrinth emitter with a flow channel width of $0.7 \mathrm{~mm}$ was $1.02-2.11 \%$, therefore, the reliability of the numerical simulated calculation is described. The calculated results are shown in Table 2 and Figure 4.

Table 2. The relative error of the flow rate.

\begin{tabular}{cccccccccc}
\hline \multirow{2}{*}{ Method } & \multicolumn{10}{c}{ Pressure Head (m) } \\
\cline { 2 - 10 } & $\mathbf{5}$ & $\mathbf{7 . 5}$ & $\mathbf{1 0}$ & $\mathbf{1 2 . 5}$ & $\mathbf{1 5}$ & $\mathbf{1 7 . 5}$ & $\mathbf{2 0}$ & $\mathbf{2 2 . 5}$ & $\mathbf{2 5}$ \\
\hline $\begin{array}{c}\text { Simulation } \\
\text { results (L/h) }\end{array}$ & 1.99 & 2.42 & 2.76 & 3.06 & 3.32 & 3.58 & 3.80 & 4.08 & 4.21 \\
\hline $\begin{array}{c}\text { Experimental } \\
\text { results (L/h) }\end{array}$ & 1.97 & 2.37 & 2.71 & 3.00 & 3.27 & 3.51 & 3.73 & 3.94 & 4.13 \\
\hline Relative error & $1.02 \%$ & $2.11 \%$ & $1.85 \%$ & $2.00 \%$ & $1.53 \%$ & $1.99 \%$ & $1.88 \%$ & $2.03 \%$ & $1.94 \%$ \\
\hline
\end{tabular}

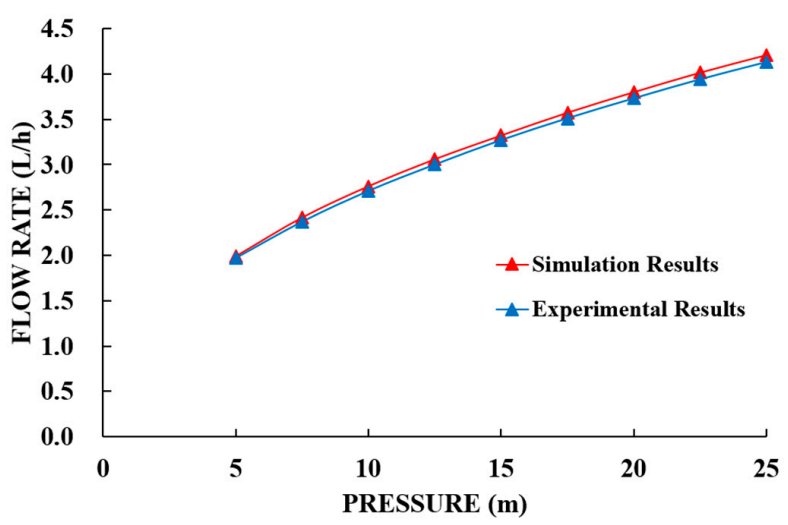

Figure 4. Curves of relationships of pressure versus simulated and experimented flow rate. 


\subsection{Flow Rate-Pressure Curve of the Emitter}

The simulation results of A, B, C, and D emitters were analyzed within 5-15 m pressure head loss in this article, obtaining the flow rate-pressure relationship; the flow coefficient, $k$; and the flow index, $x$. The data are shown in Table 3 . The calculating equation of the slope of the flow rate-pressure curve of each emitter at $6,8,10,12,14 \mathrm{~m}$ pressure head, is $q^{\prime}=k \cdot x \cdot h^{(x-1)}$; the calculation results are shown in Table 4 .

Table 3. Flow rate-pressure relationship of the emitter.

\begin{tabular}{ccc}
\hline Type & $k$ & $x$ \\
\hline $\mathrm{A}$ & 2.019 & 0.549 \\
\hline $\mathrm{B}_{1}$ & 1.903 & 0.523 \\
\hline $\mathrm{B}_{2}$ & 1.770 & 0.515 \\
\hline $\mathrm{B}_{3}$ & 1.670 & 0.508 \\
\hline $\mathrm{C}_{1}$ & 1.995 & 0.556 \\
\hline $\mathrm{C}_{2}$ & 1.958 & 0.563 \\
\hline $\mathrm{C}_{3}$ & 1.935 & 0.568 \\
\hline $\mathrm{D}$ & 1.576 & 0.603 \\
\hline
\end{tabular}

Table 4. The calculation results of the flow rate-pressure curve slopes.

\begin{tabular}{ccccccccc}
\hline Pressure Head/m & $\mathbf{C}_{\mathbf{3}}$ & $\mathbf{C}_{\mathbf{2}}$ & $\mathbf{C}_{\mathbf{1}}$ & $\mathbf{A}$ & $\mathbf{D}$ & $\mathbf{B}_{\mathbf{1}}$ & $\mathbf{B}_{\mathbf{2}}$ & $\mathbf{B}_{\mathbf{3}}$ \\
\hline 6 & 0.507 & 0.504 & 0.501 & 0.494 & 0.466 & 0.424 & 0.382 & 0.351 \\
\hline 8 & 0.447 & 0.445 & 0.441 & 0.434 & 0.416 & 0.370 & 0.332 & 0.305 \\
\hline 10 & 0.406 & 0.404 & 0.400 & 0.392 & 0.381 & 0.332 & 0.298 & 0.273 \\
\hline 12 & 0.375 & 0.373 & 0.369 & 0.361 & 0.354 & 0.305 & 0.273 & 0.250 \\
\hline 14 & 0.351 & 0.348 & 0.344 & 0.337 & 0.333 & 0.283 & 0.253 & 0.231 \\
\hline
\end{tabular}

From Tables 3 and 4, it can be observed that the flow rate-pressure relationship and the slope of the $C$ emitter curves are approximately the same. The $C_{1}$ emitter has the biggest flow coefficient (1.995), and the $C_{3}$ emitter has the smallest flow coefficient (1.935), with a difference of 0.06 . The $C_{3}$ emitter has the biggest flow index (0.568), while the $C_{1}$ emitter has the smallest flow index (0.556), with a difference of 0.012 . The slope of the $C_{3}$ emitter's flow rate-pressure curve is the biggest, while that of the $C_{1}$ emitter is the smallest; the maximum difference is 0.007 (at $14 \mathrm{~m}$ pressure head). This shows that after adding internal teeth to the vortex areas in the lateral channel of different units, the number of internal teeth has a minor effect on the hydraulic performance of the emitter. In addition, the smallest flow coefficient of the $C$ emitters $\left(1.935, \mathrm{C}_{3}\right.$ emitter) is $4.2 \%$ smaller than that of the A emitter, which is 2.019. The biggest flow index of $C$ emitters $\left(0.568, C_{3}\right.$ emitter) is $3.5 \%$ bigger than that of the A emitter, which is 0.549 . At the same time, the slope of the $\mathrm{C}$ emitter's flow rate-pressure curve is bigger than that of the A emitter. This indicates that after adding internal teeth to vortex areas in the lateral channel of different units, the emitter's hydraulic performance does not improve, but decreases.

In summary, the $\mathrm{A}, \mathrm{B}, \mathrm{D}$, and $\mathrm{C}_{1}$ emitters (which has the best hydraulic performance among $C$ emitters) are selected for comparative analysis. The flow rate-pressure curves of the $A, B, C_{1}$, and $D$ emitters are shown in Figure 5. The $A$ in the legend represents A emitter, and so on. 


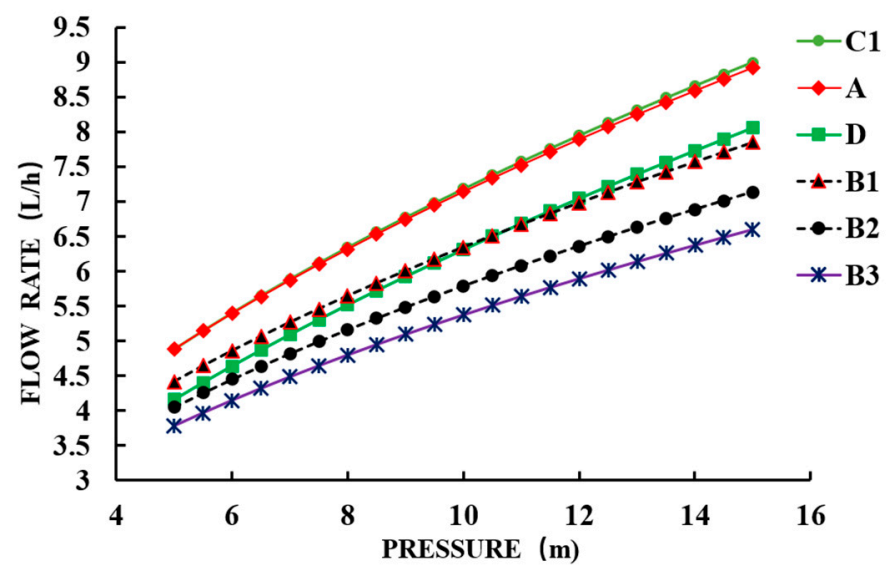

Figure 5. Flow rate-pressure curve of emitters.

From Table 4 and Figure 5, it can be observed that the slopes of the B emitters flow rate-pressure curves are smaller than that of the $\mathrm{A}$ emitter, and the maximum curve slopes of the $B_{1}, B_{2}$, and $B_{3}$ emitters decrease $16.0 \%, 24.9 \%$, and $31.5 \%$ (at $14 \mathrm{~m}$ pressure head), respectively. This shows that the sensitivity of the $\mathrm{B}$ emitters flow rate to the inlet pressure is lower than that of the A emitter; the hydraulic performance is improved, and with the increase in the number of internal teeth, there is also an increase in improvement of the hydraulic performance of the emitter. Due to lengthening the vertical channel, the energy dissipation in the channel is increased, and the slope of the $\mathrm{D}$ emitters flow rate-pressure curve is smaller than that of the A emitter but bigger than that of the B emitters. From this, we can see that in the case of increasing the same energy loss, the method of lengthening the vertical channel to increase the energy loss has less of an effect on the improvement to emitter hydraulic performance than adding internal teeth to vortex-free areas in the lateral channel of different units does.

\subsection{Analysis of Flow Field in Emitter Channels}

Figures 6 and 7 show the streamlined diagrams in the channel of the A and D emitter at the velocity of $1.1 \mathrm{~m} / \mathrm{s}$. It can be seen that the vortex in the A emitter mainly exists in the lateral channel in Figure 6. From Figure 8, after adding internal teeth to the vortex-free areas in the A emitter's lateral channel of different units, we can see that although the $B$ emitter's main flow squeezes the original vortex around the internal teeth; a new vortex appears behind the tooth, and a bigger vortex group appears in the vertical channel behind the tooth. From Figure 9, After adding internal teeth to vortex areas in the A emitter's lateral channel of different units, not only do the internal teeth destroy the original vortex, but no vortex is formed behind the tooth and in the vertical channel. At the same time, it is known from the previous section that the B emitter's hydraulic performance is better than that of the A emitter, while the hydraulic performance of the $C_{1}$ emitter is similar to that of the A emitter, and even less than that of the A emitter. This indicates that after adding internal teeth at different positions in the flow channel of the emitter, the number and distribution of vortexes in the flow channel changes, which, in turn, influences the hydraulic performance of the emitter.

Table 5 shows the sum of the vortex characteristics in a flow channel unit of the A, B, $\mathrm{C}_{1}$, and $\mathrm{D}$ emitters. The vortex intensity is defined as $\omega \times A$, where $A$ is the cross-sectional area of the vortex; $\omega$ is the rotational angular velocity, $\omega=\frac{v}{r} ; r$ is the equivalent radius of the vortex area; $v$ is the average tangential velocity at the boundary of the vortex area [25]. From Table 5, it can be observed that the number, the sum of area, and the intensity of the vortex in the $\mathrm{B}$ emitters are the largest in a flow channel unit. Compared with the $\mathrm{A}$ emitter, the sum of intensity of the vortex in the $B_{1}, B_{2}$, and $B_{3}$ emitters increases by 1.8 times, 3 times, 3.2 times, respectively. In Figure 7, the number of vortexes in the D emitter is the same as that in the A emitter, but the sum of intensity of the vortex is $7.5 \%$ bigger than that 
of the A emitter from Table 5, therefore, the slope of the D emitters flow rate-pressure curve is slightly smaller than that of the A emitter, and the hydraulic performance is slightly improved. Although the number of vortexes in the $C_{1}$ emitter is more than that of the A emitter, the sum of intensity of the vortex is $39.6 \%$ smaller than that of the A emitter. The number of vortexes in the $C_{1}$ emitter is the same as that of the $B_{1}$ emitter, but the sum of intensity of the vortex is only $21.3 \%$ of that of the $B_{1}$ emitter. This indicates that the existence of the vortex in the flow channel and the increase in its intensity are the main reasons for the improvement to the emitter's hydraulic performance.

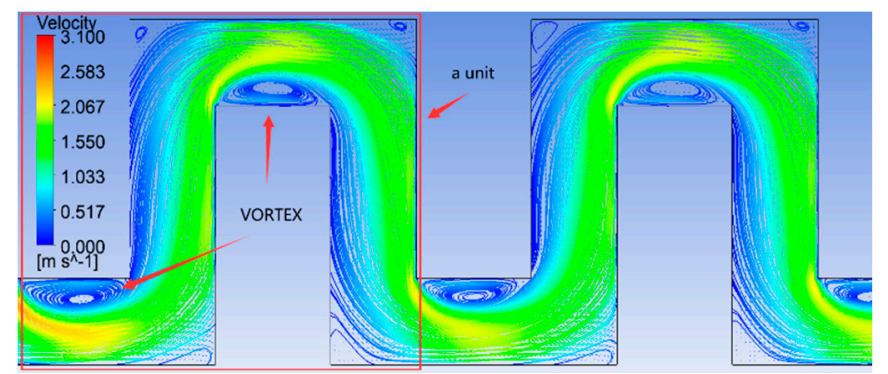

Figure 6. Streamlined diagram of the A emitter.

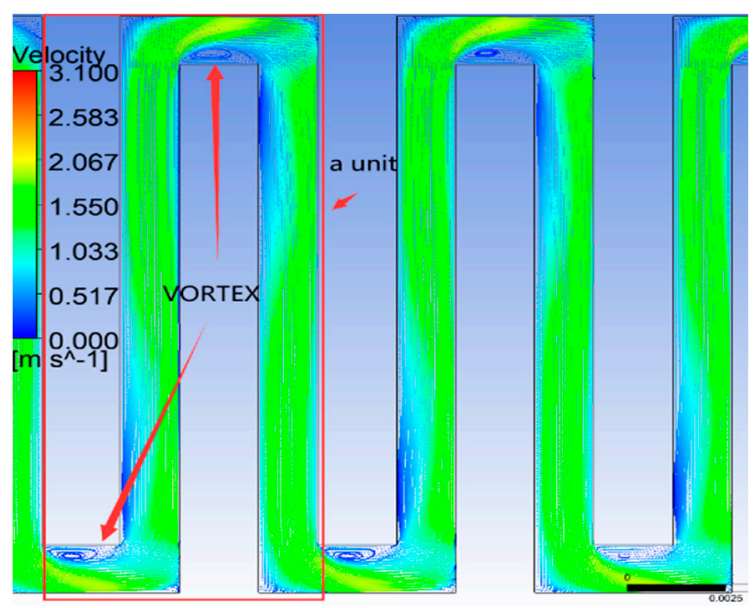

Figure 7. Streamlined diagram of the D emitter.

Table 5. Vortex characteristics (in a channel unit).

\begin{tabular}{cccc}
\hline Type & Vortex Numbers & Total Vortex Area $/ \mathbf{m m}^{\mathbf{2}}$ & Total Vortex Intensity \\
\hline $\mathrm{A}$ & 2 & 1.480 & 1.689 \\
\hline $\mathrm{B}_{1}$ & 5 & 4.970 & 4.790 \\
\hline $\mathrm{B}_{2}$ & 8 & 9.498 & 6.787 \\
\hline $\mathrm{B}_{3}$ & 8 & 9.536 & 7.125 \\
\hline $\mathrm{C}_{1}$ & 5 & 0.720 & 1.020 \\
\hline $\mathrm{D}$ & 2 & 1.790 & 1.815 \\
\hline
\end{tabular}

\subsection{Flow Velocity Distribution in the Emitter}

To further analyze the reasons for vortex formation, we extracted the intersection-lines velocity distribution, where $\mathrm{P}_{1}$ and $\mathrm{P}_{2}$ 's cross-sections intersect with the center plane of the depth direction of the channel, in the A, B, $C_{1}$, and D emitters (as shown in Figure 10). The velocity distribution is shown in Figures 11 and 12 . The $A$ in the legend represents the A emitter, and so on. 


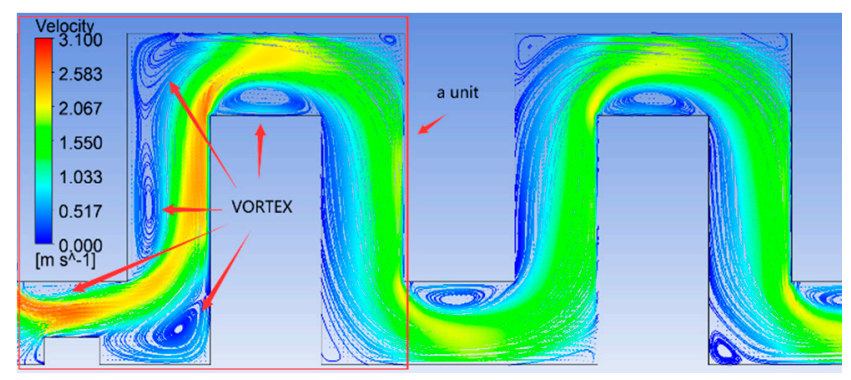

(a)

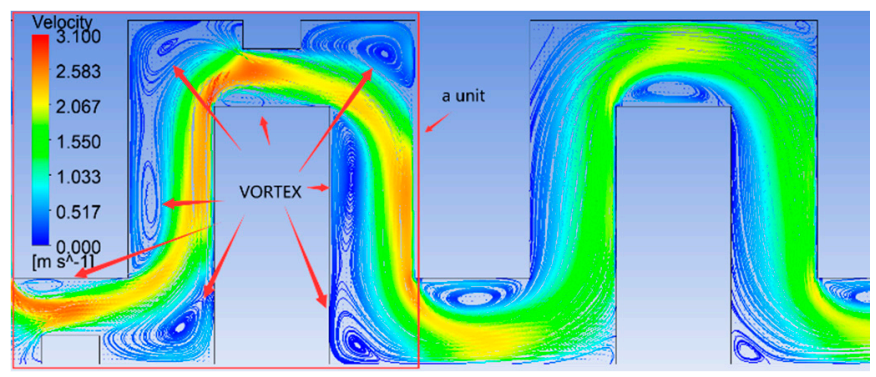

(b)

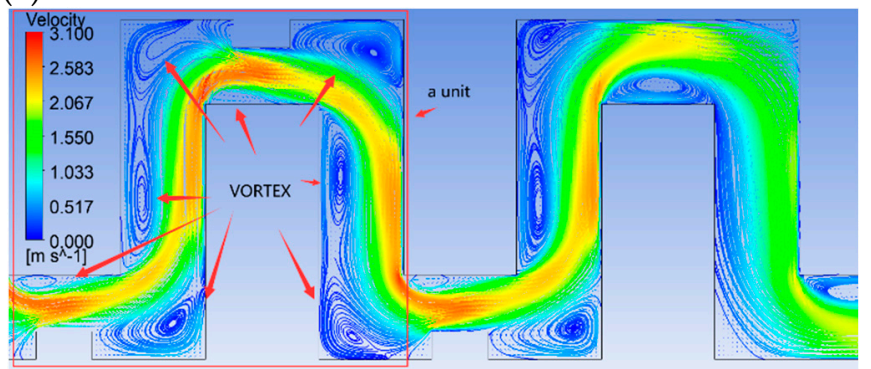

(c)

Figure 8. Streamlined diagram of the B emitters. (a) Streamlined diagram of the $\mathrm{B}_{1}$ emitter; (b) Scheme 2 emitter; (c) streamlined diagram of the $B_{3}$ emitter.

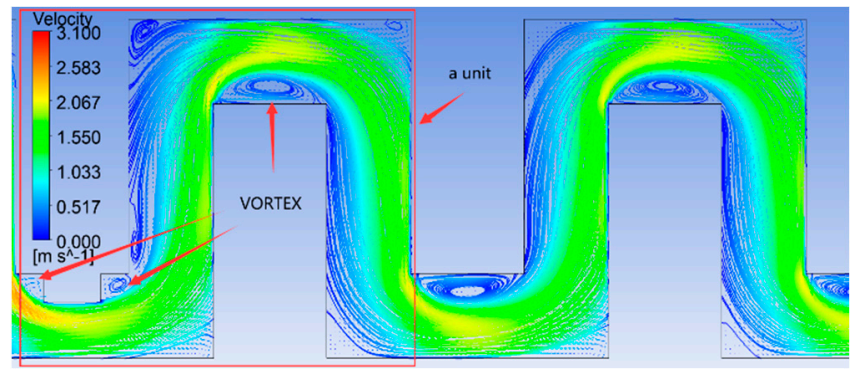

Figure 9. Streamlined diagram of the $C_{1}$ emitter.

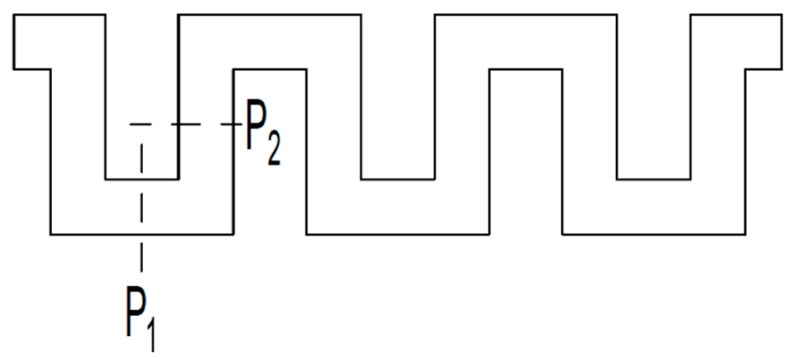

Figure 10. Depth directions center plane schematic diagram.

As shown in Figure 11, due to the presence of internal teeth, in the B emitters, the shape of $\mathrm{P}_{1}$ 's velocity distribution curve becomes "thin," and the curve heads' velocity gradient is bigger. This causes the turning fluid to shrink further and exacerbates the generation of a new vortex in the corner of the channel behind the internal tooth, as shown in Figure 8. The $P_{1}$ 's velocity distribution curve in the $C_{1}$ and $D$ emitters is similar to that in the A emitter; the curve heads' velocity gradient is small, so that no new vortex is generated. In addition, as shown in Figure 9, after adding internal teeth to the original vortex area of the $C_{1}$ emitter, the original vortex is destroyed, which not only fails to make the fluid shrink further; but also causes the velocity distribution at $\mathrm{P}_{1}$ 's position to become more uniform and reduces the turbulence degree of the flow field and energy dissipation. 
This also further explains the reason why the hydraulic performance of the $C_{1}$ emitter slightly decreases.

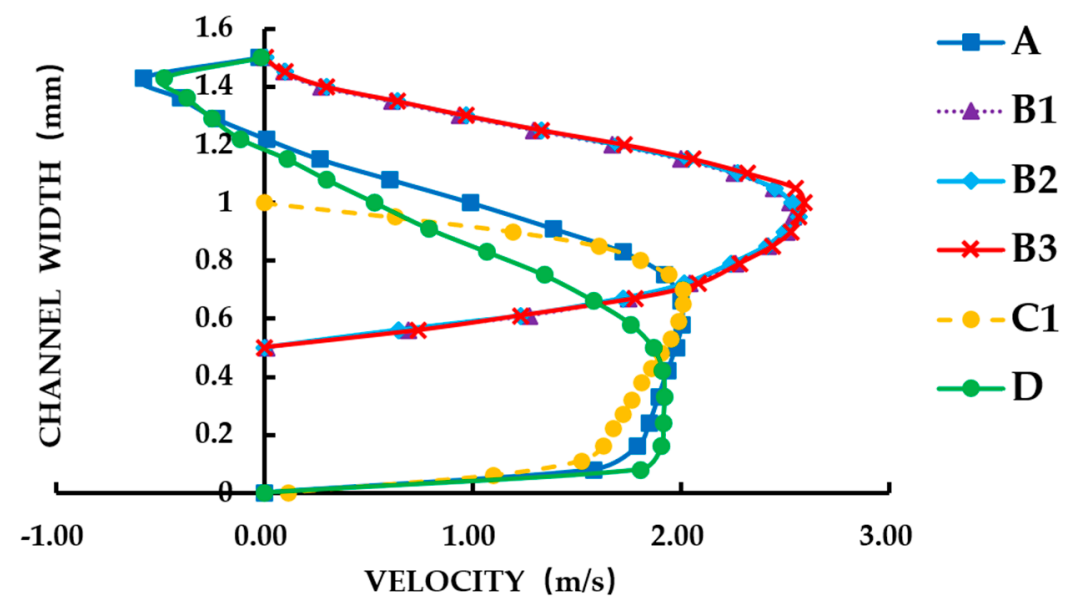

Figure 11. Velocity distribution in $\mathrm{P}_{1}$ position of $\mathrm{A}, \mathrm{B}, \mathrm{C}_{1}$ and $\mathrm{D}$ emitter.

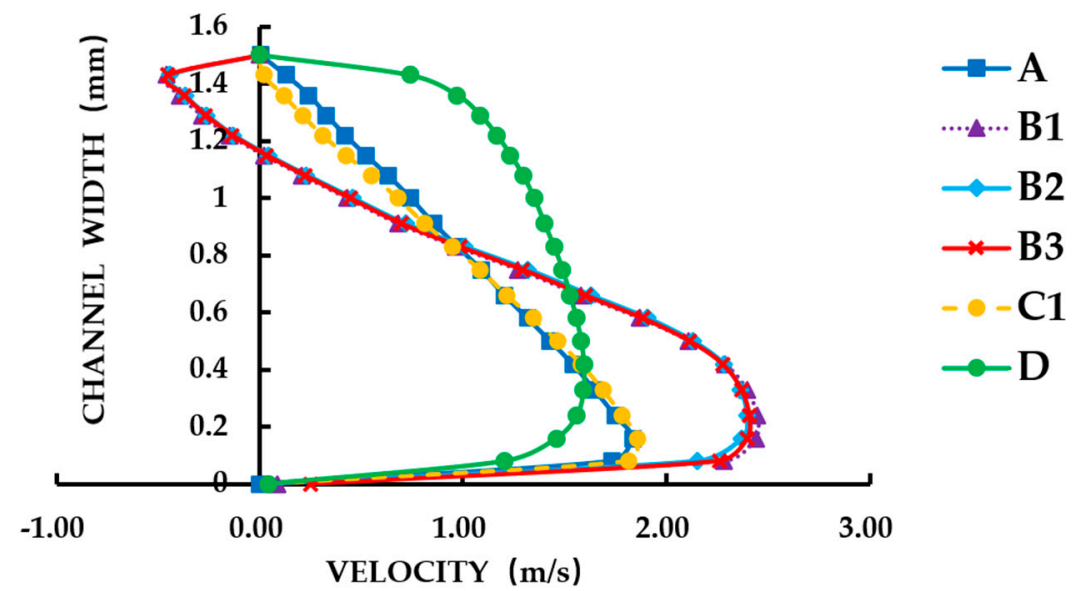

Figure 12. Velocity distribution in $\mathrm{P}_{2}$ position of $\mathrm{A}, \mathrm{B}, \mathrm{C}_{1}$ and $\mathrm{D}$ emitter.

As shown in Figure 12, the curves velocity gradient remains large in the B emitter's vertical channel $P_{2}$ position behind the internal tooth; the maximum velocity is $30 \%$ bigger than that of the A emitter, and new vortexes are generated. This indicates that the internal teeth accelerate the main flow velocity in the vertical channel behind the internal tooth and turn the original low-speed area into vortex areas, which greatly increase the degree of turbulence in the vertical flow channel and intensify energy dissipation. This is also one of the reasons why the hydraulic performance is improved. The vertical channel $\mathrm{P}_{2}$ 's velocity distribution of the $C_{1}$ and the $A$ emitter is basically the same. Due to the lengthening of the vertical channel, the D emitter's velocity distribution is close to that of the turbulent flow in the direct channel, which tends to be uniform. The maximum velocity is $13 \%$ smaller than that of the A emitter.

In this article, we changed the channel structure of the emitter by adding internal teeth to the lateral flow channel and by lengthening the vertical flow channel, and the hydraulic performance of the emitter changed. Based on the above analysis, the change in the flow channel structure of the emitter changes the velocity distribution in the flow field. The addition of internal teeth to the vortex-free area increases the maximum flow velocity and its gradient in the toothed flow channel unit. The increase in the velocity gradient exacerbates the generation of vortexes in the flow channel, and the increase in the number and intensity of the vortexes in the flow channel is the internal reason for the improvement to the hydraulic performance of the emitter. In addition, adding internal 
teeth at a reasonable position can turn the original low-speed area into a vortex area. The full development of the vortex improves the self-cleaning ability of the water flow to the flow channel wall and improves the anti-clogging ability of the emitter to a certain extent [26].

\section{Conclusions}

Analyzing the simulation results of the A, B, C, and D labyrinth emitters, the following conclusions can be drawn:

1. Adding internal teeth to vortex-free areas in the lateral channel of different units of rectangular labyrinth emitters can improve hydraulic performance, and doing so to vortex areas not only fails to improve the hydraulic performance but can reduce it.

2. Adding internal teeth is not the reason for the improvement in the emitter's hydraulic performance. The increase in the number, distribution, and intensity of vortex in the flow field is the internal reason for the improvement in the emitter's hydraulic performance.

3. In the case of increasing the same energy loss, the method of lengthening the vertical flow channel has less of an effect on the improvement in the emitter's hydraulic performance than adding internal teeth to increase the vortex characteristics.

4. The change in the flow channel structure promotes the formation of a larger velocity gradient in the flow field, and the increase in the velocity gradient exacerbates the generation of the vortex in the flow field.

5. Changing the flow channel structure to improve the emitter's hydraulic performance can promote an increase in the number and intensity of vortexes in the emitter and avoid damage to the original vortex structure in the flow field.

Author Contributions: C.W. edited the original draft; Z.L. reviewed and edited the draft; J.M. provided the funding. All authors have read and agreed to the published version of the manuscript.

Funding: This work was supported by the National Natural Science Foundation of China (52079085).

Institutional Review Board Statement: Not applicable.

Informed Consent Statement: Not applicable.

Data Availability Statement: The data that support the finding of this study are available from the corresponding author upon reasonable request.

Acknowledgments: The authors thank the School of Water Resources Science and Engineering for providing the site for experiment and collecting data.

Conflicts of Interest: The authors declare no conflict of interest.

\section{References}

1. Zhang, J.; Zhao, W.; Lu, B. Rapid prediction of hydraulic performance for emitters with labyrinth channels. J. Irrig. Drain. Eng. 2013, 139, 414-418. [CrossRef]

2. Yunkai, L.; Ji, F. Progress in measurement of hydrodynamic characteristics in drip irrigation emitters. J. Drain. Irrig. Mach. Eng. 2014, 32, 86-92, (In Chinese with English Abstract).

3. Xiaohong, W. Structural Design and Experimental Study on Hydraulic Performance of Emitters with Labyrinth Channel. Master's Thesis, Xi'an University of Technology, Xi'an, China, 2006.

4. Keller, J.; Karmeli, D. Trickle irrigation design parameters. Trans. ASAE 1974, 17, 0678-0684. [CrossRef]

5. Mattar, M.A.; Alamoud, A.I.; Al-Othman, A.A.; Elansary, H.O.; Farah, A.-H.H. Hydraulic performance of labyrinth-channel emitters: Experimental study, ann, and gep modeling. Irrig. Sci. 2020, 38, 1-16. [CrossRef]

6. Liming, Y. Relations between the hydraulic performance and the structural parameters of emitter. J. Chang. Univ. Sci. Technol. 2011, 08, 30-35, (In Chinese with English Abstract)

7. Qiaoli, X.; Wenquan, N.; Lianzhong, L. Effect of tooth angle and pitch of labyrinth channel on performance of emitter. J. Drain. Irrig. Mach. Eng. 2013, 31, 449-455, (In Chinese with English Abstract)

8. Ye, T.; Minjie, W.; Ming, L.; Guojun, D. The effect of drip irrigation emitter channel structure parameters of triangular type on its hydraulic performances. Model. Simul. 2018, 7, 55-62, (In Chinese with English Abstract) 
9. Jiyang, T.; Dan, B.; Changjiang, R.; Wang, X. Analysis on hydraulic performance of bidirectional flow channel of drip irrigation emitter. Trans. CSAE 2013, 89-94, (In Chinese with English Abstract)

10. Chunjing, L.; Dunbing, T.; Hua, H.; Xingqiang, C. Hydraulic performance robustness analysis for drip irrigation triangle labyrinth channel of emitter. Trans. CSAM 2013, 44, 67-72, (In Chinese with English Abstract)

11. Souza, W.d.J.; Rodrigues Sinobas, L.; Sanchez, R.; Botrel, T.A.; Coelho, R.D. Prototype emitter for use in subsurface drip irrigation: Manufacturing, hydraulic evaluation and experimental analyses. Biosyst. Eng. 2014, 128, 41-51. [CrossRef]

12. Yan, D.; Yang, P.; Ren, S.; Li, Y.; Xu, T. Numerical study on flow property in dentate path of drip emitters. N. Z. J. Agric. Res. 2007, $50,705-712$.

13. Xing, S.; Wang, Z.; Zhang, J.; Liu, N.; Zhou, B. Simulation and verification of hydraulic performance and energy dissipation mechanism of perforated drip irrigation emitters. Water 2021, 13, 171. [CrossRef]

14. Camp, C.R. Subsurface drip irrigation: A review. Trans. ASAE 1998, 41, 1353-1367. [CrossRef]

15. Yunkai, L.; Peiling, Y.; Shumei, R. General review on several fundamental points of design theory about flow path in drip irrigation emitters. Trans. CSAM 2006, 37, 145-149, (In Chinese with English Abstract)

16. Adin, A.; Sacks, M. Dripper-clogging factors in wastewater irrigation. J. Irrig. Drain. Eng. 1991, 117, 813-826. [CrossRef]

17. Nakayama, F.S.; Bucks, D.A. Water quality in drip/trickle irrigation: A review. Irrig. Sci. 1991, 12, 187-192. [CrossRef]

18. Chen, X.; Wu, P.; Fan, X.; Niu, W. Numerical simulation of structural parameters using CFD and anti-clogging design analyse on drip emitter. J. Irrig. Drain. 2008, 27, 35-38, (In Chinese with English Abstract)

19. Chang, Y.; Niu, W.; Wang, W. Numerical simulation and flow analysis of labyrinth path of drip irrigation emitters. J. Northwest AEF Univ. 2009, 37, 203-208, (In Chinese with English Abstract)

20. $\mathrm{Xu}, \mathrm{T}$; Z Zhang, L. Influence and analysis of structure design and optimization on the performance of a pit drip irrigation emitter* Irrig. Drain. 2020, 69, 633-645. [CrossRef]

21. Miaoye, K. Influence of Double Internal Tooth Parameters on Hydraulic Performance of Labyrinth Irrigation Device. Master's Thesis, Taiyuan University of Technology, Taiyuan, China, 2018.

22. Fujun, W. Computational Fluid Dynamics Analysis-CFD Software Principle and Application; Tsinghua University Press: Beijing, China, 2004; Volume 1, pp. 7-12.

23. Yongxin, L.; Guangyong, L.; Xiangyu, Q.; Wang, J. Modeling of hydraulic characteristics through labyrinth emitter in drip irrigation using computational fluid dynamics. Trans. CSAE 2005, 21, 12-16, (In Chinese with English Abstract)

24. Wei, Q.; Shi, Y.; Dong, W.; Gang, L.; Huang, S. Study on hydraulic performance of drip emitters by computational fluid dynamics. Agric. Water Manag. 2006, 84, 130-136. [CrossRef]

25. Zhichang, Z. Hydraulics, 2nd ed.; China Water \& Power Press: Beijing, China, 2016; Volume 7, pp. $272-277$.

26. Feng, J.; Li, Y.; Wang, W.; Xue, S. Effect of optimization forms of flow path on emitter hydraulic and anti-clogging performance in drip irrigation system. Irrig. Sci. 2017, 36, 37-47. [CrossRef] 